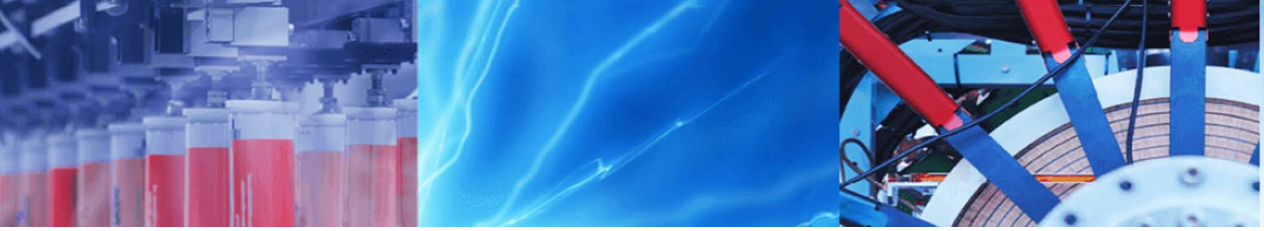

Research Article

\title{
Simulation and analysis of three-phase parallel inverter using multicarrier PWM control schemes
}

\author{
Manikanta Swamy Dasari ${ }^{1} \cdot$ Venkatesan Mani $^{1}$
}

Received: 4 January 2020 / Accepted: 15 April 2020 / Published online: 24 April 2020

(c) Springer Nature Switzerland AG 2020

\begin{abstract}
Simulation and analysis of three-phase parallel inverter using multicarrier pulse width modulation such as phase disposition (PD), phase opposition disposition (POD) and alternate phase alternate disposition (APOD) are presented in this article. In this proposed work, reduced active switching count, transformers, single DC input, a high degree of modularity and redundancy are key merits and also suitable for renewable energy systems. The proposed three-phase five-level multilevel inverter with single DC source using a three-phase transformer is controlled by multicarrier pulse width modulation schemes. To generate switching pulses for five-level inverter, four carrier signals can be compared with a reference signal. The performance of the inverter is examined by using PD, POD, and APOD by modulation index (MI) starting from 0.4 to 1 . Furthermore, the over-modulation region is also analyzed in this paper. The effectiveness of the system is analyzed in terms of total harmonic distortion by varying the MI of the inverter. The simulation results are verified through MATLAB/Simulink.
\end{abstract}

Keywords Three-phase MLI $\cdot$ Reduced switch count $\cdot$ MC-PWM $\cdot$ THD

\section{Introduction}

In recent years, the various multilevel inverter topologies have been utilized for the power conversion purpose. But, development of the multilevel inverter topologies is growing for high power and high voltage applications especially renewable energy applications. Out of the various renewable energy sources, solar PV energy is highly preferable for electrical power generation [1]. The different types of MLIs topologies have been used for the conversion of renewable energy power into the AC power [2,3]. MLIs topologies are offered the highest conversion efficiency, lower THD, lower electromagnetic interference and lower passive filtering requirements. Furthermore, it is possible to modify new topologies with a reduced number of components [4]. There are three kinds of MLI topologies (1) diode clamped (2) flying capacitor and (3) cascaded
$\mathrm{H}$-bridge inverter [5]. The many authors have been investigated cascaded $\mathrm{H}$-bridge inverters for grid-connected applications. Three-phase two-level inverter is the most commonly used structure for renewable energy systems applications [6]. But it has some own drawbacks, limitation of voltage level, passive filtering requirement, and THD. To eliminate the drawbacks of the three-phase two-level inverter, three-phase inverter topology can be formed by using the six, single-phase two-level inverter that has been proposed [7]. The interesting fact in this topology is that there is no necessity for a transformer in the inverter module, but to feed power to the grid it requires a transformer owing to the common-mode current. It uses only one DC source and several single-phase transformers are connected in series at the output side. Furthermore, a threephase inverter is presented along with a low frequency transformer $[8,9]$. It is the all-encompassing variant of the

Manikanta Swamy Dasari, dmks_eeep@vignan.ac.in; Venkatesan Mani, venkatesangct@gmail.com | ${ }^{1}$ Department of Electrical and Electronics Engineering, Vignan's Foundation for Science, Technology, and Research, Vadlamudi, Guntur, India. 
inverters created by $[8,9]$. This proposed topology is an extended version of the paper [10]. A three-phase inverter is presented by space vector PWM in [11]. A three-phase four-wire system is developed for grid application in [12]. Recently, the three-phase inverter has been introduced for PV applications $[13,14]$. To solve the aforementioned problems, a new three-phase inverter has been developed in this paper, in which three-phase voltages were obtained from a single DC-link and it is possible only, secondary terminals of the transformer are star connection. Furthermore, higher-order harmonics are decreased with the help of the transformer which is highly adaptable for utility applications and isolation between input and output are remarkable benefits. Many authors have been investigated by various carrier-based PWM techniques [15, 16]. In this article, the three-phase parallel inverter can be controlled by MC-PWM (APOD, POD, and PD). The inverter performance can be evaluated in terms of THD.

\section{Proposed systems}

The block diagram of the proposed system is shown in Fig. 1. The proposed inverter circuit includes three singlephase five-level inverters. An individual single-phase inverter produces a five-level output voltage from a common DC-link voltage. A single-phase inverter is formed by connecting auxiliary inverter along with an $\mathrm{H}$-bridge inverter. An auxiliary inverter is constructed by single IGBT along with four power diodes. In this three-phase inverter, $\mathrm{H}$-bridge inverter consists of four IGBTs and out of these, $S_{\mathrm{a} 3}$ and $S_{\mathrm{a} 4}$ are operated at a rate of the fundamental frequency. The switches $S_{a 1}, S_{a 2}$, and $S_{a 5}$ in the auxiliary circuit are operated at the rate of the carrier frequency.

It is observed from Fig. 2, phase-A is comprised of normal $\mathrm{H}$-bridge inverter $\left(S_{\mathrm{a} 1}-S_{\mathrm{a} 4}\right)$ along with auxiliary an inverter $\left(S_{a 5}\right)$. Similarly, phase-B is comprised of $S_{b 1}-S_{b 4}$ and $S_{b 5}$ and phase- $C$ is comprised of $S_{c 1}-S_{c 4}$ and $S_{c 5}$. Each single-phase inverter is generated $325 \mathrm{~V}$ from the $D C$ link when gating pulses are applied from the control circuit. The voltage of the DC link is supposed to be greater than the inverter output voltage $\left(>\sqrt{2} \times V_{0}\right)$. Failing to meet this condition, an inverter is unable to guarantee the power flow to the load. Three single-phase five-level inverters are given to the 12 terminal of the three-phase transformer, and the neutral points are shorted. The key merits are that

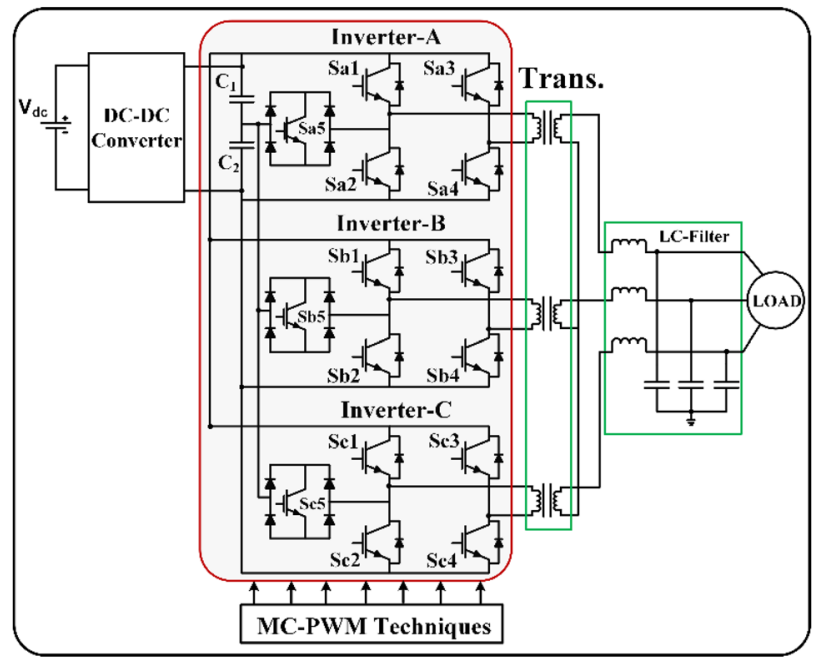

Fig. 2 Proposed power circuit
Fig. 1 Block diagram of the proposed system

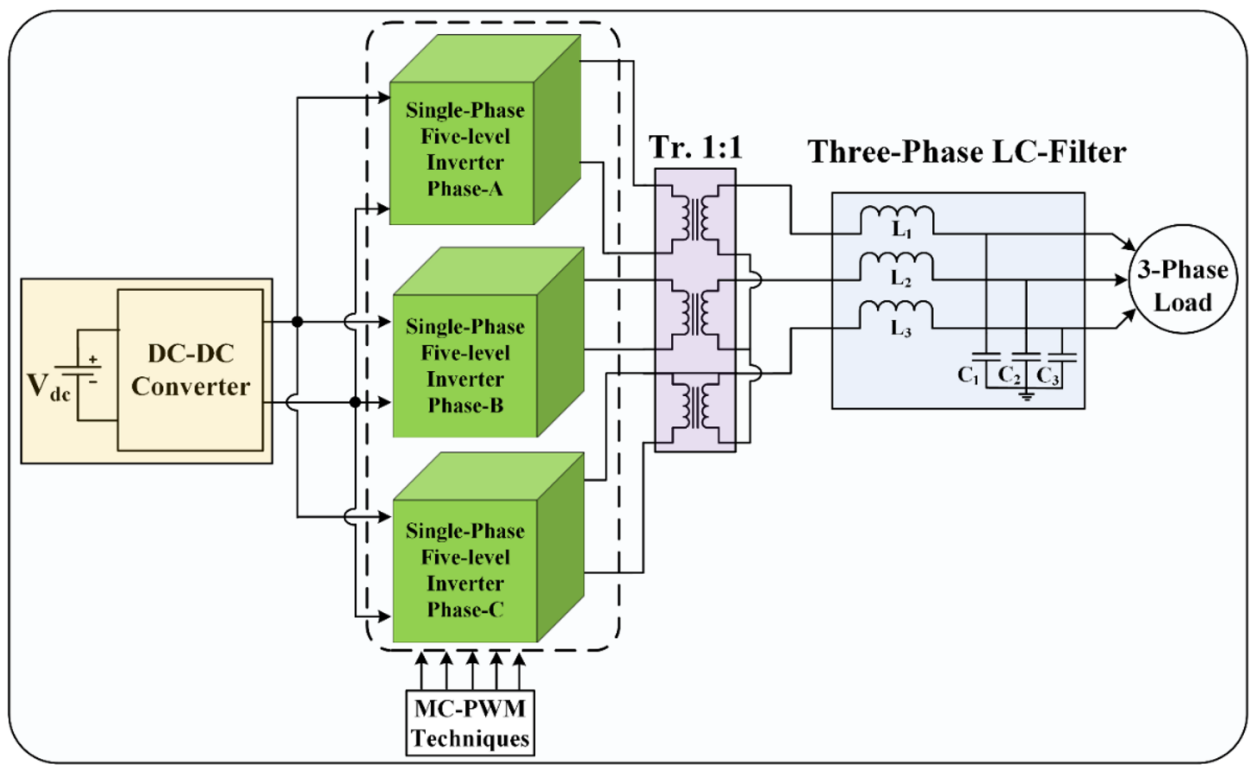


it obtains a higher output voltage with a reduced number of active devices, transformer, DC input source, and simplified control circuits. They are operated in five states and corresponding voltage states are as follows: When the output voltage is equal to zero, $S_{\mathrm{a} 5}$ is completely OFF and others are in either ON or OFF the switching table and other four modes of operation are shown in Fig. 3.

Switches $S_{a} 1, S_{a} 2$, and $S_{a} 5$ operate at $20 \mathrm{kHz}$ of switching frequency, and one leg of the $\mathrm{H}$-bridge inverter $\left(\mathrm{S}_{\mathrm{a} 3}\right.$ and $S_{a 4}$ ) operates in the $50 \mathrm{~Hz}$ frequency. The proposed inverter generates a five-level output voltage from the common DC-link voltage. The fault detection and replacement of faulty devices are very easy in this inverter. Actually a generic phase-leg can be decomposed into $S_{\mathrm{a} 3}$ switch cell and $S_{\mathrm{a} 4}$ switch cell depending on the load current directions. There is no question that dead-time is not required for either a $S_{a 3}$ switch cell or an $S_{a 4}$ switch cell because both switch cells are configured with a controllable switch in series with an uncontrollable diode [21].

\section{Multicarrier-based PWM techniques}

The PWM control technique is the most effective control scheme for controlling the three-phase inverter. In this proposed method, carrier-based PWM schemes are used such as PD, POD, and APOD have been applied. These are also called constant frequency techniques; generation switching pulses for an $N$ level inverter, an $N-1$ carrier is required. An amplitude modulation index (MI) and frequency modulation for a multilevel inverter are as follows

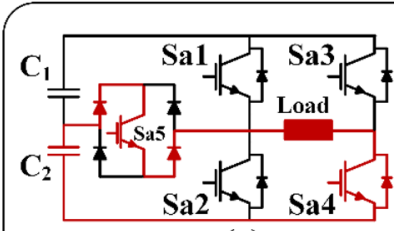

(a)

$\mathrm{Sa} 4$ and $\mathrm{Sa} 5$ are $\mathrm{ON}$ $\mathrm{Sa} 1, \mathrm{Sa} 2$ and $\mathrm{Sa} 3$ are OFF Output voltage is $=+\mathrm{Va} / 2$

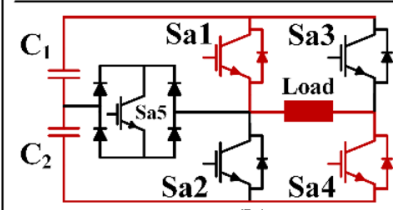

(b)

Sal and Sa4 are ON

$\mathrm{Sa} 2, \mathrm{Sa} 3$ and $\mathrm{Sa} 5$ are $\mathrm{OFF}$

Output voltage is $=+\mathrm{Va}$

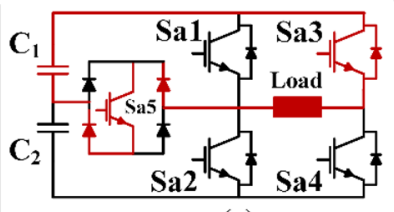

(c)

$\mathrm{Sa} 1, \mathrm{Sa} 2$ and $\mathrm{Sa} 4$ are OFF

Output voltage is $=-\mathrm{Va} / 2$

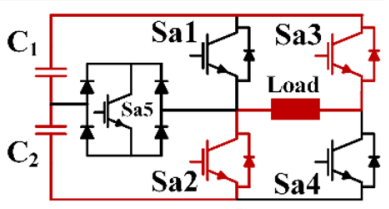

(d)

$\mathrm{Sa} 2$ and $\mathrm{Sa} 3$ are $\mathrm{ON}$

$\mathrm{Sa} 1, \mathrm{Sa} 4$ and $\mathrm{Sa} 5$ are $\mathrm{OFF}$ Output voltage is $=-\mathrm{Va}$
$\mathrm{Sa} 3$ and $\mathrm{Sa} 5$ are $\mathrm{ON}$

Fig. 3 Modes of operation and voltage levels
$M_{\mathrm{inv}}=\frac{A_{\mathrm{m}}}{(m-1) A_{\mathrm{c}}}$

$F_{\text {inv }}=\frac{f_{\mathrm{c}}}{f_{\mathrm{m}}}$

where $A_{\mathrm{m}}$ and $A_{\mathrm{c}}$ are the peak amplitude of modulation and carrier signal, respectively.

The frequency of the carrier and modulating signals are termed as $f_{c}$ and $f_{m^{\prime}}$, respectively. The realization of switching logic to the inverter is implemented by using logic gates. The generalized switching logic diagram is shown in Fig. 4. The reference and carrier arrangement for PD, POD, and APOD are shown in Figs. 5, 6 and 7 [20].

In the APOD technique, each carrier is phase-shifted by $180^{\circ}$ from its adjacent carrier. In the POD technique, two carriers waves are arranged above the zero reference and other two carrier waves are arranged below the zero reference. Above the zero reference, carrier waves are in phase

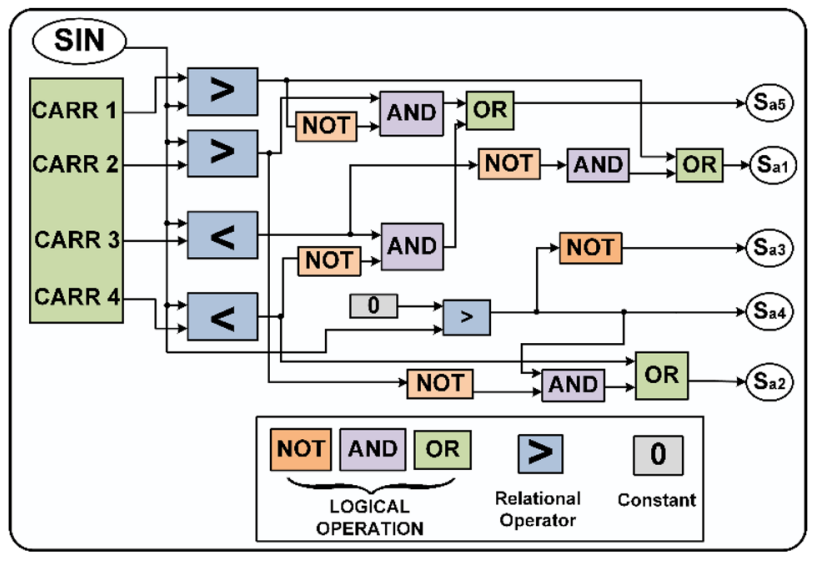

Fig. 4 Switching pattern realization using logic gates

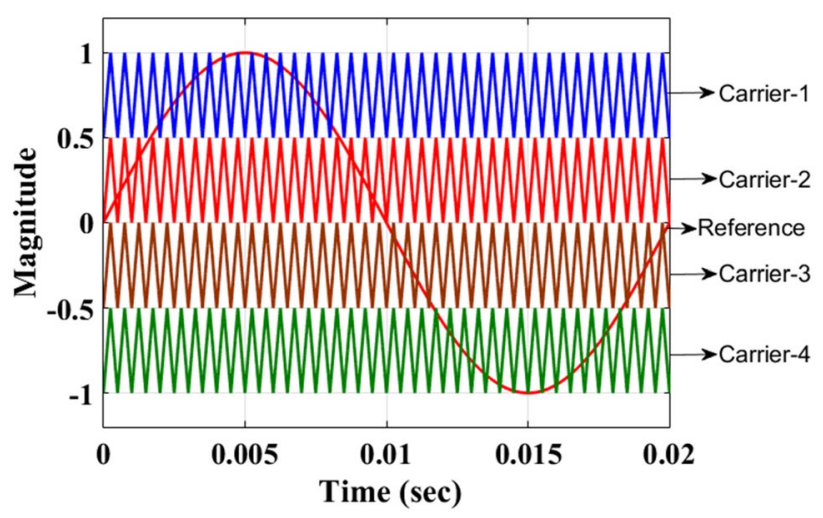

Fig. 5 Reference and carrier arrangement for PD 


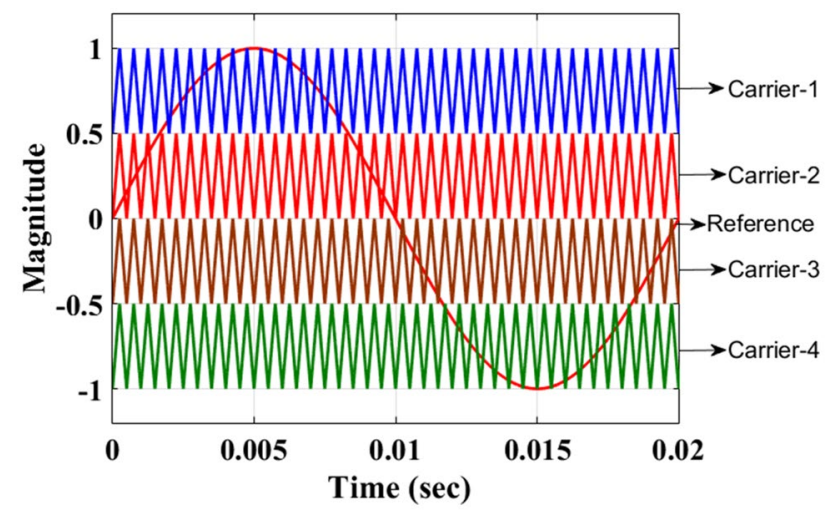

Fig. 6 Reference and carrier arrangement for POD

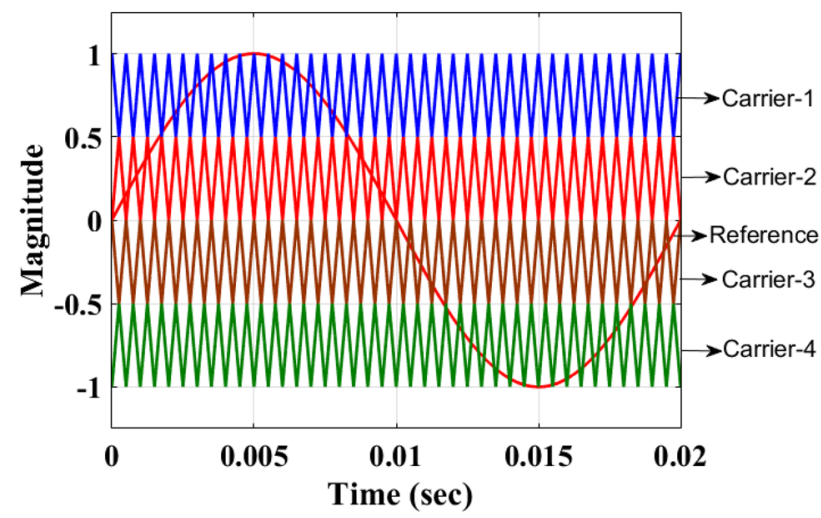

Fig. 7 Reference and carrier arrangement for APOD

with each other and below the zero reference, carrier waves maintain $180^{\circ}$ phase shift (opposite) with the above the zero reference carrier waves. In the PD techniques, all carrier waves are in phase with each other. The switching pulses to the inverter switches are shown in Fig. 8.

\section{Simulation results and discussion}

The simulation of proposed PWM controlled three-phase inverter is carried out by using MATLAB/Simulink, and obtained simulation results are discussed. The inductor and capacitor values for the filter are $1 \mathrm{mH}$ and $2 \mu \mathrm{F}$. The simulation parameters used in the proposed system are shown in Table 1.

\subsection{Phase disposition (PD)}

In this phase disposition technique, the four carrier signals are compared to the reference signal. These four carrier

SN Applied Sciences

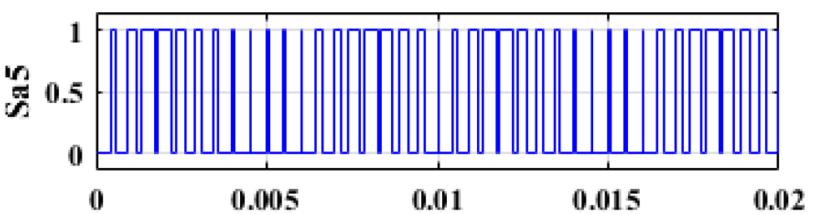

(b)

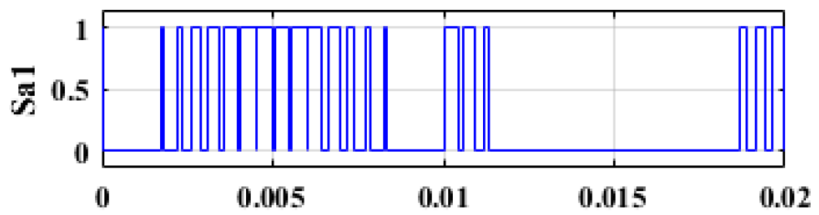

(c)

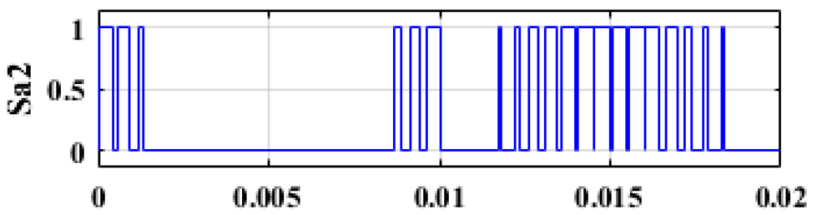

(d)

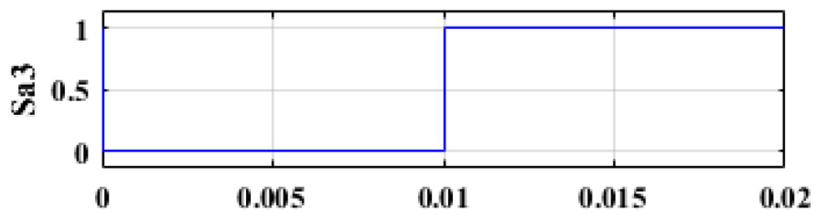

(e)

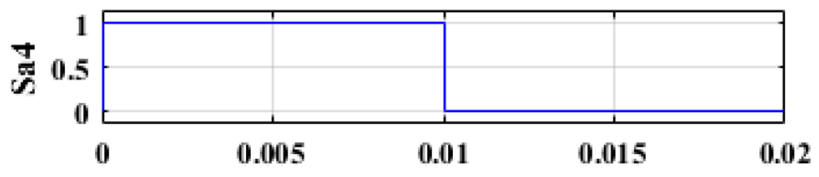

(f)

Time (sec)

Fig. 8 Switching pulses

Table 1 Simulation parameter values

\begin{tabular}{ll}
\hline Parameters & Specifications \\
\hline Inverter input voltage & $340 \mathrm{~V}$ \\
Inverter output voltage per phase (RMS) & $231 \mathrm{~V}$ \\
Output current (RMS) & $1.44 \mathrm{~A}$ \\
Output power & $997.92 \mathrm{~W}$ \\
Fundamental frequency & $50 \mathrm{~Hz}$ \\
Switching frequency & $20 \mathrm{kHz}$ \\
Inductance & $1 \mathrm{e}-3 \mathrm{H}$ \\
Capacitance & $2 \mathrm{e}-6 \mathrm{~F}$ \\
Resistive load & $1000 \Omega$ \\
Transformer primary and secondary voltages & $400 \mathrm{~V}$ \\
Transformer rating & $3 \mathrm{KVA}$
\end{tabular}



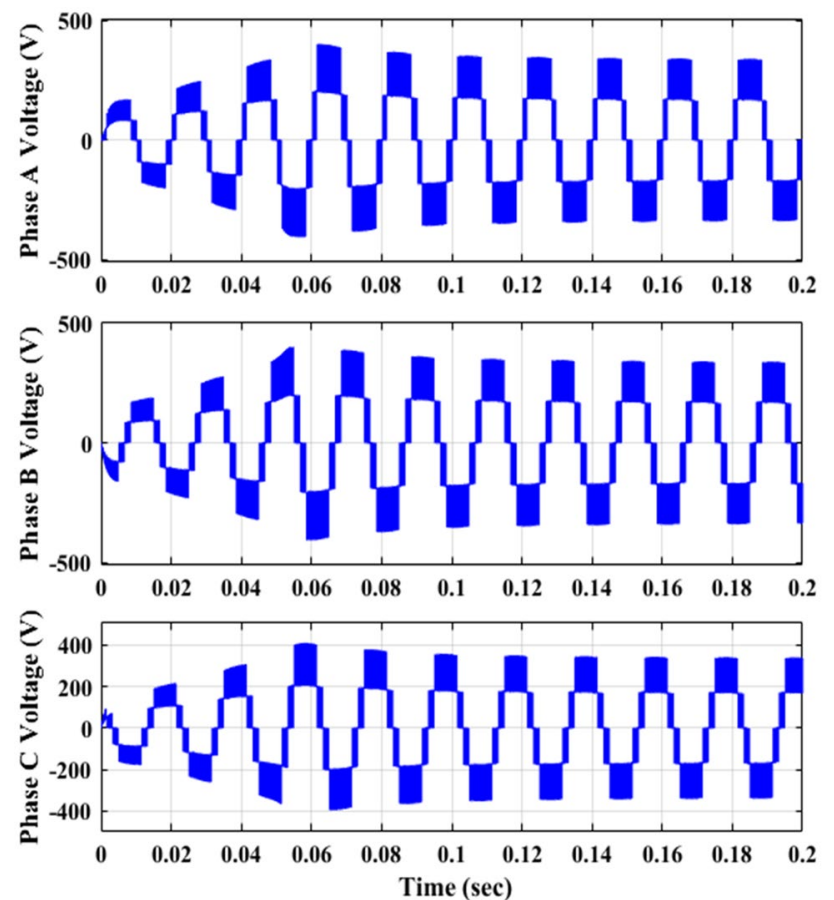

Fig. 9 Five-level waveforms of PD
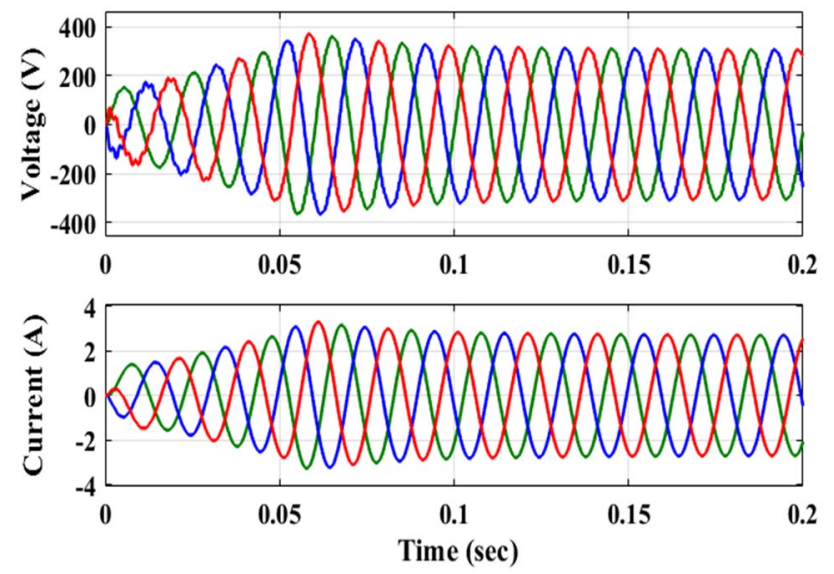

Fig. 10 Three-phase voltage and current waveforms

signals are having equal amplitudes and in phase each other.

To generate appropriate pulses to the inverter, four carrier signals are compared with a sinusoidal carrier signal $(50 \mathrm{~Hz})$ and it is shown in Fig. 5, and the switching pattern is also given in Fig. 8; the $y$-axis is an amplitude in volts, and the $x$-axis is time in seconds. Simulation results of five-level output voltages are depicted in Fig. 9. The three-phase output voltage, current and THD profile are depicted in Figs. 10 and 11, respectively. The THD generated by the

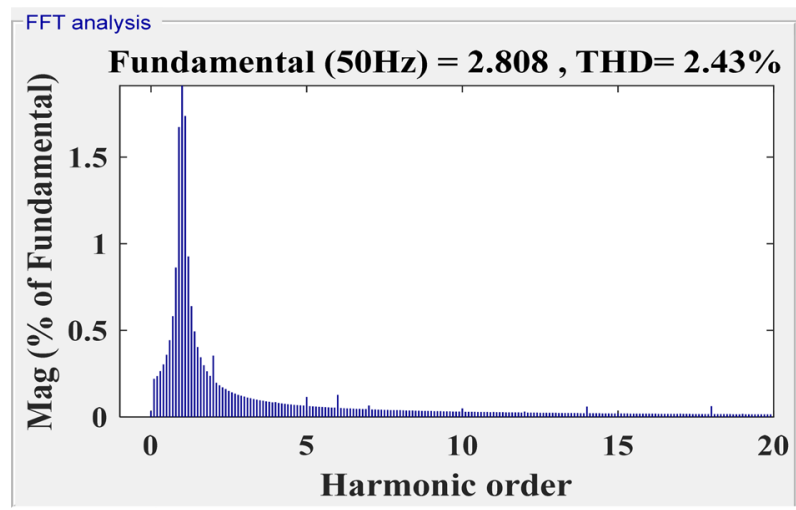

Fig. 11 THD at $M I=1$
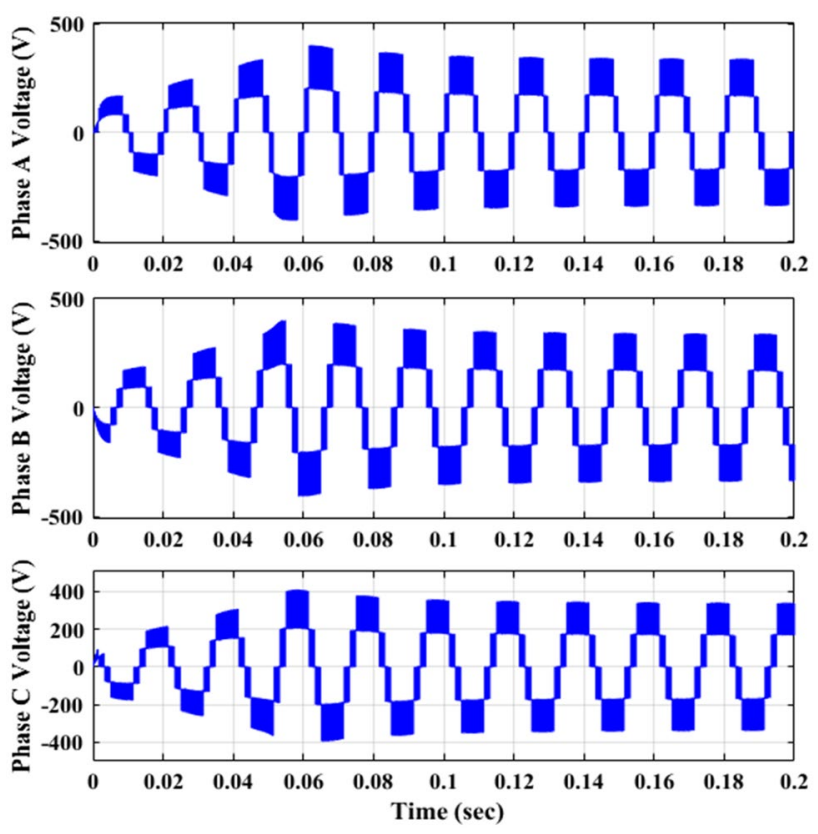

Fig. 12 Waveforms of POD (five levels)

inverter is about $2.43 \%$ at $\mathrm{Ml}$ equal to 1 using PD-PWM techniques.

\subsection{Phase opposition disposition (POD)}

In the POD technique, two carriers waves are arranged above the zero reference and other two carrier waves are arranged below the zero reference. Above the zero reference, carrier waves are in phase with each other and below the zero reference, carrier waves maintain $180^{\circ}$ phase shift (opposite) with the above the zero reference carrier waves. All carrier signals are maintained equal amplitude and frequency, but the difference in phase shift is shown in Fig. 6; 

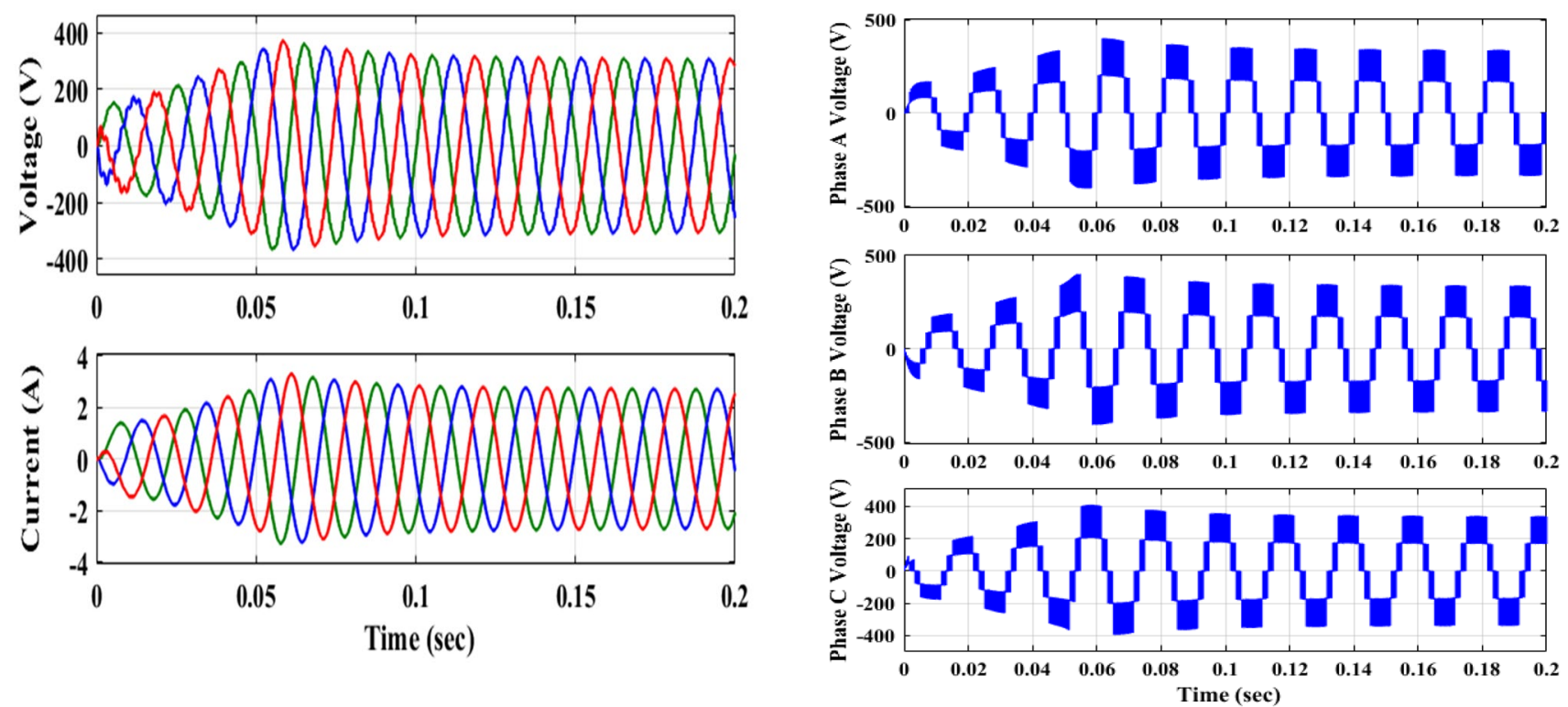

Fig. 13 Three-phase voltage and current waveforms of POD

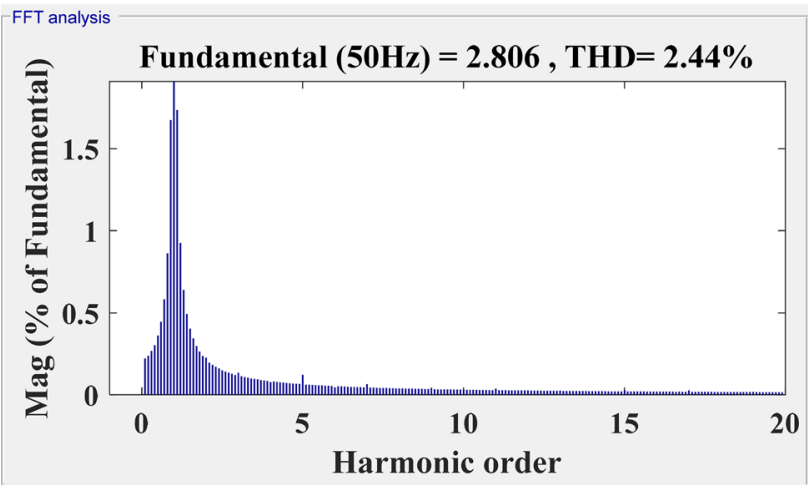

Fig. 15 Five-level waveforms of APOD

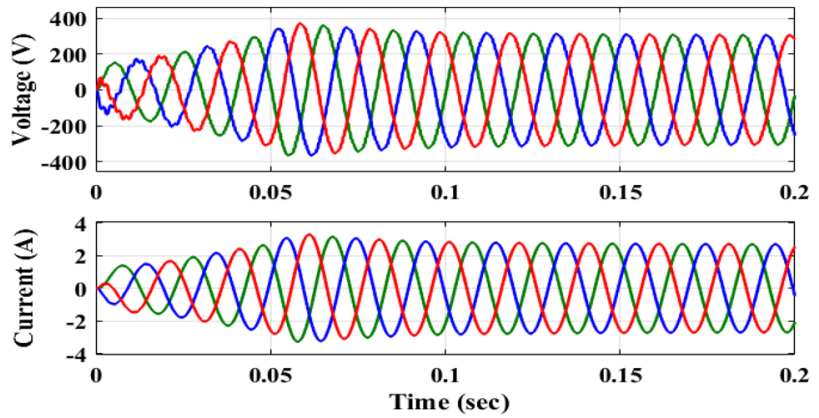

Fig. $14 \mathrm{THD}$ at $\mathrm{MI}=1$

Fig. 16 Three-phase voltage and current waveforms of APOD

the $y$-axis is an amplitude in volts, and the $x$-axis is time in seconds.

Simulation results of five-level output voltages are depicted in Fig. 12. The three-phase output voltage, current and THD profile are depicted in Figs. 13 and 14, respectively. The THD generated by the inverter is about $2.44 \%$ at MI equal to 1 using POD-PWM techniques.

\subsection{Alternate phase opposition disposition (APOD)}

In this APOD technique, all the carrier signals are phaseshifted by $180^{\circ}$ from the adjacent carriers. In APOD PWM, zero references are placed in the middle of the carriers.

Above the zero references, carriers are positive carriers and below the zero references are negative carriers. In this, all carriers are maintaining $180^{\circ}$ shifted with each other and it is shown in Fig. 7; the $y$-axis is an amplitude in volts, and the $x$-axis is time in seconds.

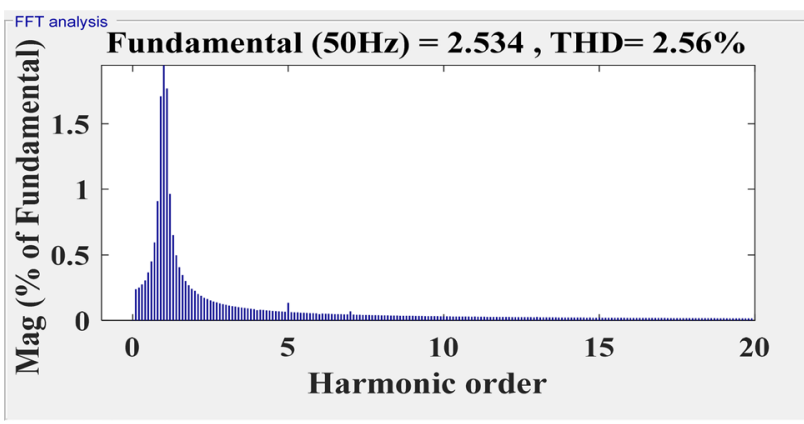

Fig. 17 THD at Ml-1

Simulation results of five-level output voltages are depicted in Fig. 15. The three-phase output voltage, current and THD profile are depicted in Figs. 16 and 17, 


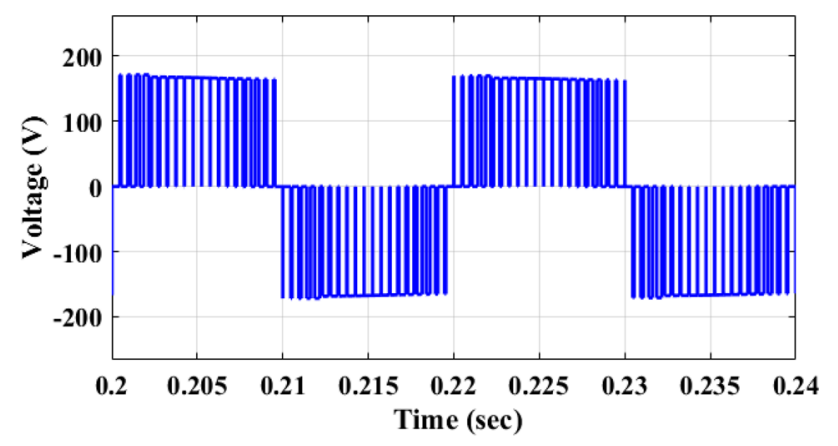

Fig. 18 Inverter output voltage at MI-0.5

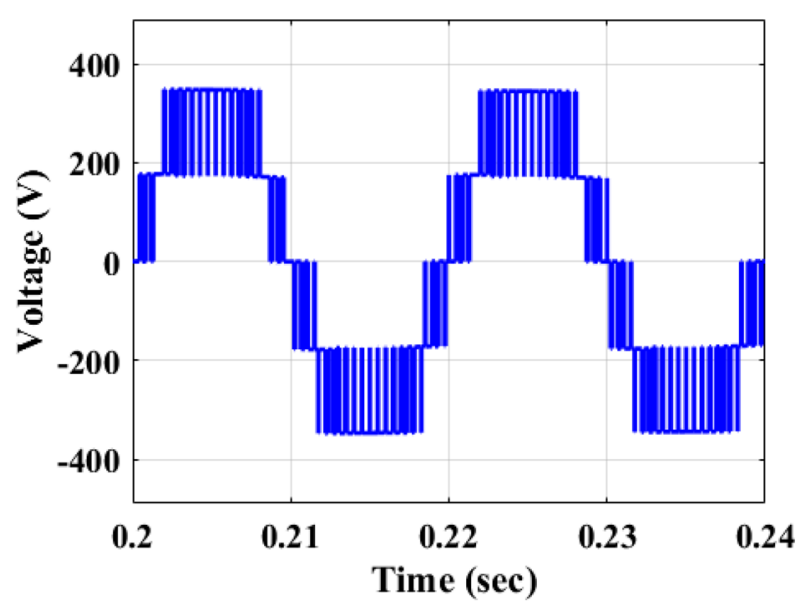

Fig. 19 Inverter output voltage at MI-0.9

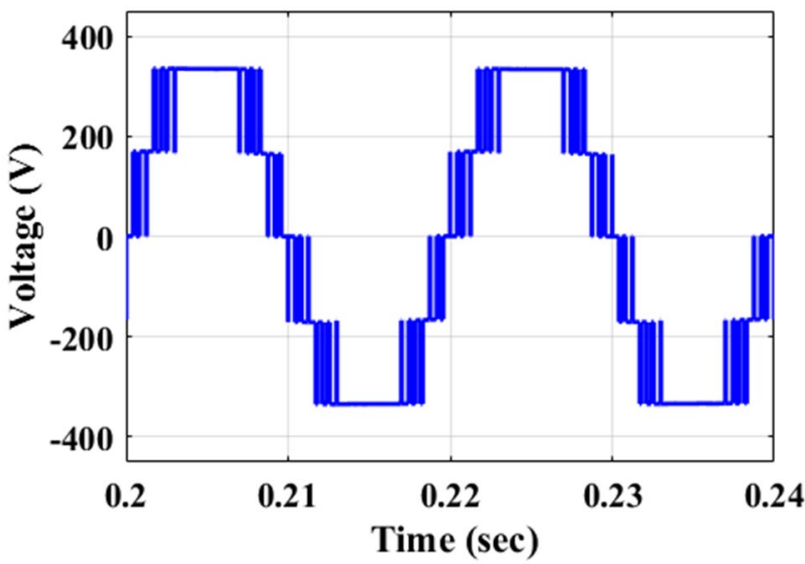

Fig. 20 Inverter output voltage at Ml-1.2

respectively. The THD generated by the inverter is about $2.56 \%$ at $\mathrm{MI}=1$ using APOD-PWM techniques. Figures 18,19 and 20 show the inverter output voltage with an $\mathrm{Ml}$ of $0.5,0.9$ and 1.2 , respectively.
Table 2 Device and components comparison

\begin{tabular}{lllll}
\hline Device and components & \multicolumn{2}{l}{ References } & Proposed \\
\cline { 2 - 4 } & {$[18]$} & {$[5]$} & {$[19]$} & \\
\hline DC bus capacitors & 06 & 01 & 03 & 03 \\
Diodes & - & - & - & 12 \\
Input DC source & 06 & 01 & 03 & 01 \\
Transformers & - & 06 & 01 & 01 \\
Active switches & 24 & 24 & 18 & 15 \\
No. of levels & 05 & 07 & 05 & 05 \\
\hline
\end{tabular}

The different components are used in the three-phase inverter, and it is tabulated in Table 2. In [18], the fivelevel inverter has been proposed by the authors. In this topology, six input DC sources and 24 switches are used. Similarly, components are utilized in $[5,19]$. The proposed inverter uses only 15 switches, single DC input, and threephase transformer.

\section{Interpretation of simulation results}

In this section, interpretation of simulation results of PD-PWM, POD-PWM and APOD-PWM techniques is presented in Tables 3, 4 and 5, respectively. The carrier-based PWM (PD, POD, and APOD) techniques have been applied to examine the performance of the inverter with different modulation index. In this, a star-connected resistive $(1000 \Omega)$ load is considered, so phase voltage, line voltage, and current values are taken in Tables 3, 4 and 5 with different MC-PWM techniques. From Table 3, the percentage of voltage and current THD is obtained from the various modulation indexes starting from 40 to $100 \%$. Percentages of THDs are obtained from inverter without a filter. $15.74 \%$ is obtained from the inverter for the modulation index 1 (one), whereas $38.59 \%$ of THD is obtained at 0.4 . From Table 4, the percentage of voltage and current THD is obtained from the various modulation indexes starting from 40 to $100 \%$. Percentages of THDs are obtained from inverter without a filter. $19.87 \%$ is obtained from the inverter for the modulation index 1 (one), whereas $61.81 \%$ of THD is obtained at 0.4 . From Table 5, the percentage of voltage and current THD is obtained from the various modulation indexes starting from 40 to $100 \%$. Percentages of THDs are obtained from inverter without a filter. $23.42 \%$ is obtained from the inverter for the modulation index 1 (one), whereas $61.81 \%$ of THD is obtained at 0.4 . From the simulation results, harmonic content developed by the inverter is a minimum of $15.74 \%$ compared to the other PWM techniques. Hence, it is concluded PD-PWM techniques significantly improve the performances of the inverter compared to the others and current THD is also 
Table 3 Simulation results summary of PD

\begin{tabular}{|c|c|c|c|c|c|c|}
\hline \multirow[t]{2}{*}{ MI } & \multicolumn{2}{|l|}{$V_{\mathrm{Ph}}$} & \multicolumn{2}{|l|}{$V_{\mathrm{L}}$} & \multicolumn{2}{|c|}{$I_{\mathrm{L}}(\% \mathrm{THD})$} \\
\hline & Voltage & $\% \mathrm{THD}$ & Voltage & $\%$ THD & Current & $\%$ THD \\
\hline 1 & 215.3 & 15.74 & 372.9 & 15.72 & 1.876 & 2.43 \\
\hline 0.9 & 194.9 & 16 & 337.5 & 16 & 1.697 & 2.46 \\
\hline 0.8 & 175 & 20.2 & 303.1 & 20 & 1.514 & 2.65 \\
\hline 0.5 & 114.3 & 32.62 & 198 & 32.61 & 0.959 & 3.86 \\
\hline 0.4 & 94.96 & 38.59 & 164.5 & 38.56 & 0.781 & 3.14 \\
\hline
\end{tabular}

Table 4 Simulation results summary-POD

Table 5 Simulation results summary-APOD

\begin{tabular}{|c|c|c|c|c|c|c|}
\hline \multirow[t]{2}{*}{ MI } & \multicolumn{2}{|l|}{$V_{\mathrm{Ph}}$} & \multicolumn{2}{|l|}{$V_{\mathrm{L}}$} & \multicolumn{2}{|c|}{$I_{\mathrm{L}}(\% \mathrm{THD})$} \\
\hline & Voltage & $\%$ THD & Voltage & $\%$ THD & Current & $\% \mathrm{THD}$ \\
\hline 1 & 216.8 & 19.87 & 375.5 & 19.87 & 1.875 & 2.44 \\
\hline 0.9 & 199.6 & 27.46 & 345.8 & 27.53 & 1.697 & 2.57 \\
\hline 0.8 & 180.7 & 32.71 & 312.9 & 32.80 & 1.514 & 2.79 \\
\hline 0.5 & 115.9 & 36.84 & 200.7 & 36.89 & 0.959 & 3.88 \\
\hline 0.4 & 104.1 & 61.81 & 180.4 & 61.82 & 0.781 & 3.56 \\
\hline
\end{tabular}

\begin{tabular}{|c|c|c|c|c|c|c|}
\hline \multirow[t]{2}{*}{$\overline{\mathrm{MI}}$} & \multicolumn{2}{|l|}{$V_{\mathrm{Ph}}$} & \multicolumn{2}{|l|}{$V_{\mathrm{L}}$} & \multicolumn{2}{|c|}{$I_{\mathrm{L}}(\% \mathrm{THD})$} \\
\hline & Voltage & $\%$ THD & Voltage & $\%$ THD & Current & $\%$ THD \\
\hline 1 & 218.5 & 23.42 & 378.4 & 23.44 & 1.876 & 2.48 \\
\hline 0.9 & 199 & 26.27 & 344.7 & 26.35 & 1.697 & 2.56 \\
\hline 0.8 & 177.9 & 27.27 & 308.2 & 27.30 & 1.514 & 2.71 \\
\hline 0.5 & 115.9 & 36.84 & 200.7 & 36.89 & 0.959 & 3.88 \\
\hline 0.4 & 104.1 & 61.81 & 180.4 & 61.82 & 0.781 & 3.56 \\
\hline
\end{tabular}

within the recommended standard of IEEE. Compared to the existing topologies, the proposed three-phase fivelevel inverter has been developed with 15 active switches and only one three-phase transformer along with the single DC (SDC) source. The proposed inverter generates a five-level output voltage. Therefore, lower THD profile and lesser passive filtering requirement and higher reliability can be attained since each phase is acting independently. Hence, fault identification and rectification are very easy.

Figure 21 shows the percentage of voltage and current THD with different modulation index (from Tables 3, 4, 5).

Table 6 represents the comparison of THD with the proposed system and the existing system. The proposed system produced $2.43 \%$ of THD so as compared to other systems the proposed system produces less THD. Similarly. Figure 22 represents the bar chart of THD proposed system and existing system.

\subsection{Future work}

The future work of this research work is to implement experimental setup for grid-connected applications by using field programmable gate array (FPGA) to verify the simulation results and inverter performance.

\section{Conclusion}

The MC-PWM control based modified three-phase inverter with minimized switch count using SDC input has been presented in this paper. MC-PWM technique has been used to obtain switching pulses for the inverter switches for the proposed inverter. The switching pulses, $(N-1)$ carrier signals were compared with a single reference signal. Finally, THD comparison has been carried out for simulation results of the proposed system with a different modulation index from 40 to $100 \%$. Finally, the device and the utilization of the components of an inverter were also investigated with existing research findings. The results of the proposed inverter have been analyzed using MATLAB/Simulink. 


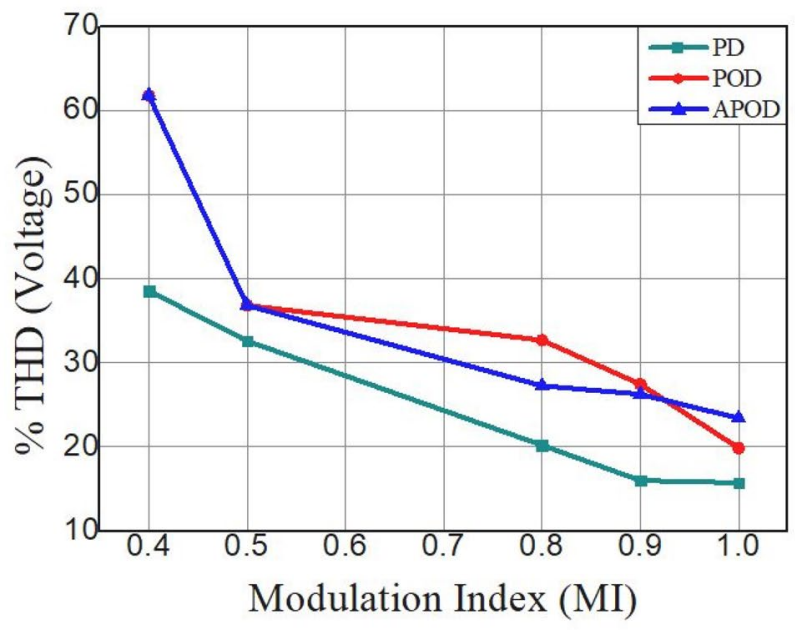

(a)

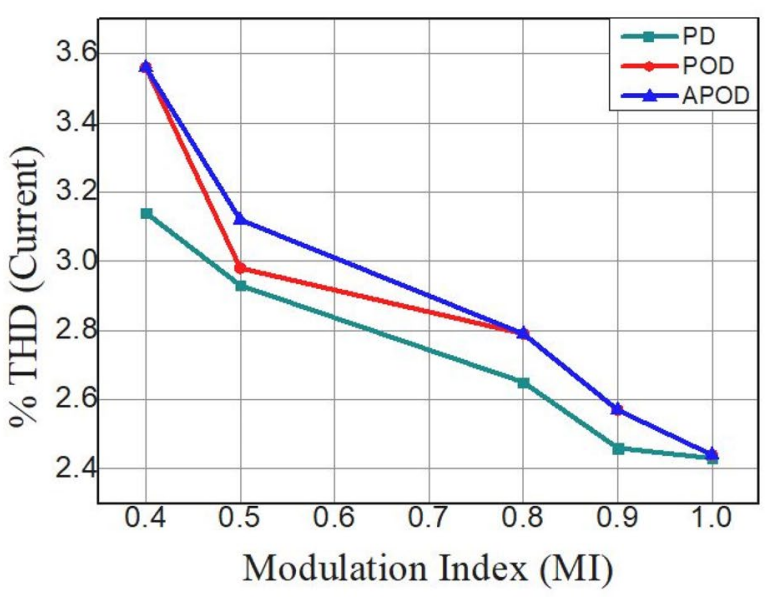

(b)

Fig. 21 Inverter THD, a voltage, b current

Table 6 THD comparison

\begin{tabular}{lll}
\hline References & \% THD & PWM technique \\
\hline$[1]$ & 5.46 & MC-PWM \\
{$[2]$} & 5.69 & MC-PWM \\
{$[8]$} & 3.39 & PS-PWM \\
{$[17]$} & 7.25 & PWM \\
{$[18]$} & 4.16 & SPWM \\
Proposed & 2.43 & MC-PWM \\
\hline
\end{tabular}

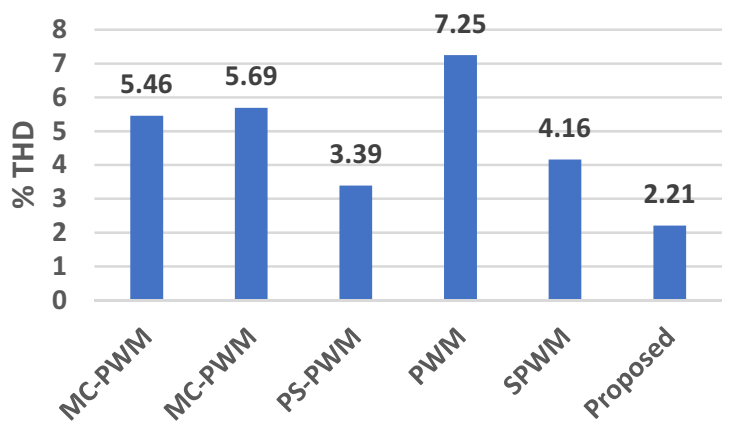

Control Techniques

Fig. 22 Bar charts of \% THD with the proposed system and existing system

\section{Compliance with ethical standards}

Conflict of interest The authors declare that there is no conflict of interest.

\section{References}

1. Holmes DG, Lipo TA (2003) Pulse width modulation for power converters: principles and practice, vol 18. Wiley, Berlin

2. Gupta KK, Jain S (2014) A novel multilevel inverter based on switched DC sources. IEEE Trans Ind Electron 61(7):3269-3278

3. Kavali J, Mittal A (2016) Analysis of various control schemes for minimal total harmonic distortion in cascaded $\mathrm{H}$-bridge multilevel inverter. Jo Electr Syst Inf Technol 3:428-441

4. Subramaniam $S$ et al (2019) Design and implementation of three phase micro inverter based PV module. J Green Eng 9(1):35-59

5. Prabaharan N, Palanisamy K (2017) A comprehensive review on reduced switch multilevel inverter topologies, modulation techniques and applications. Renew Sustain Energy Rev $76: 1248-1282$

6. Odeh $\mathrm{Cl}$ (2013) Enhanced three-phase multilevel inverter configuration. IET Power Electron 6(6):1122-1131

7. Ala G, Caruso M, Miceli R, Pellitteri F, Schettino G, Trapanese M, Viola $F$ (2019) Experimental investigation on the performances of a multilevel inverter using a field programmable gate arraybased control system. Energies 12(6):1016

8. Panda AK, Suresh Y (2012) Performance of cascaded multilevel inverter by employing single and three-phase transformers. IET Power Electron 5(9):1694-1705

9. Song SG, Kang FS, Park SJ (2019) Cascaded multilevel inverter employing three-phase transformers and single DC input. IEEE Trans Ind Electron 56(6):2005-2014

10. Rahim NA, Selvaraj J (2009) Multistring five-level inverter with novel PWM control scheme for PV application. IEEE Trans Ind Electron 57(6):2111-2123

11. Mani V, Ramachandran R, Nanjundappan D (2016) Implementation of a modified SVPWM-based three-phase inverter with reduced switches using a single DC source for a grid-connected PV system. Turk J Electr Eng Comput Scie 24:3023-3035 
12. Hintz A, Prasanna UR, Rajashekara K (2016) Comparative study of the three-phase grid-connected inverter sharing unbalanced three-phase and/or single-phase systems. IEEE Trans Ind Appl 52(6):5156-5164

13. Rajalakshmi S, Rangarajan P (2019) Investigation of modified multilevel inverter topology for PV system. Microprocess Microsyst 71:1-14. https://doi.org/10.1016/j.micpro.2019.102870

14. Venkataramanaiah J, Suresh Y, Panda AK (2017) A review on symmetric, asymmetric, hybrid and single DC sources based multilevel inverter topologies. Renew Sustain Energy Rev 76:788-812

15. McGrath BP, Holmes DG (2002) Multicarrier PWM strategies for multilevel inverters. IEEE Trans Ind Electron 49(4):858-867

16. Kumar Kalilasam R, Mani V (2018) FPGA based quasi $z$-source cascaded multilevel inverter using multicarrier PWM techniques. J Vibroeng 20(3):1544-1553

17. Barzegarkhoo R, Zamiri E, Vosoughi N, Kojabadi HM, Chang L (2016) Cascaded multilevel inverter using series connection of novel capacitor-based units with minimum switch count. IET Power Electron 9(10):2060-2075
18. Singh J, Dahiya R, Saini LM (2018) Recent research on transformer based single DC source multilevel inverter: a review. Renew Sustain Energy Rev 82:3207-3224

19. Suresh Y, Panda AK (2013) Investigation on hybrid cascaded multilevel inverter with reduced DC sources. Renew Sustain Energy Rev 26:49-59

20. Narasimhulu V, Kumar DVA, Babu CS (2019) Recital analysis of multilevel cascade $\mathrm{H}$-bridge based active power filter under load variation. SN Appl Sci 1(12):1621

21. Chen L, Peng FZ (2008) Dead-time elimination for voltage source inverters. IEEE Trans Power Electron 23(2):574-580

Publisher's Note Springer Nature remains neutral with regard to jurisdictional claims in published maps and institutional affiliations. 